International Review of Research in Open and Distributed Learning Volume 22, Number 2

May - 2021

\title{
An Analysis of Digital Education in Canada in 2017-2019
}

Dr. George Veletsianos ${ }^{1}$, Dr. Charlene A. VanLeeuwen ${ }^{1,2}$, Olga Belikov ${ }^{1}$, and Dr. Nicole Johnson ${ }^{1,3}$

${ }^{1}$ Royal Roads University; 2 University of Prince Edward Island; ${ }^{3}$ Canadian Digital Learning Research Association

\begin{abstract}
Digital education refers to in-person, blended, and fully online learning efforts, as well as attempts to capture a wide range of teaching and learning contexts which make use of digital technology. While digital education is pervasive in Canada, pan-Canadian data on digital education are relatively scarce. The Canadian Digital Learning Research Association/Association Canadienne de Recherche sur la Formation en Ligne conducted pan-Canadian surveys of higher education institutions (2017-2019), collecting data on the digital education landscape and publishing annual reports of its results. Previous analyses of the data have used quantitative approaches. However, the surveys also collected responses to open-ended questions. In this study, we report a systematic analysis of qualitative data exploring the digital education landscape in Canada and its changes over time. Findings shed light on the growth of digital education, the situated and multidimensional nature of digital education, the adoption of openness, quality, and rigour, and the development of alternative credentials.
\end{abstract}

Keywords: digital education, higher education, university, college, Canada, qualitative analysis 


\section{Introduction}

The demand for digital learning in Canada has expanded substantially over the last decade (e.g., Bates et al., 2017; Donovan et al., 2018; Johnson, 2019), with online and blended courses currently being offered by the majority of Canadian institutions of higher education (Agbra, 2018; Bates, 2018). A similar trend is reflected in the U.S., where online enrolments have been increasing for more than a decade (Seaman et al., 2018). Nevertheless, pan-Canadian data that illuminate digital learning in the Canadian postsecondary education sector are minimal. The annual surveys conducted by the Canadian Digital Learning Research Association/Association Canadienne de Recherche sur la Formation en Ligne (hereafter CDLRA) provide much-needed information and analysis. However, the published reports that result from these annual surveys focus on analyses of quantitative data. The purpose of this study was to conduct a systematic analysis of the qualitative data that were gathered in the 2017, 2018, and 2019 CDLRA pan-Canadian surveys in order to explore patterns in these data that may inform digital education practice in Canada.

\section{Rationale and Research Context}

Digital education refers to in-person, blended, and fully online learning efforts, as well as attempts to capture a wide range of teaching and learning contexts which make use of digital technology. While Canada has a long history of distance education use, researchers lack pan-Canadian data tracking use of digital learning, making it difficult to gauge comparative progress with respect to digital education, identify emerging topics of interest in the Canadian higher education sector, or identify future demands for digital education (Bates, 2018). Researchers and policymakers, therefore, often rely on proxy data to inform decisions pertaining to digital education. The absence of federal regulatory authority means that there is great variance across the country, as many education-related efforts are provincially- or institutionallyfocused (McGreal \& Anderson, 2007). As digital learning in Canada has grown over time, training and support for faculty have also become increasingly necessary (Mohr \& Shelton, 2017; VanLeeuwen et al., 2020).

Guided by a need to address these gaps, the CDLRA began conducting surveys of Canadian higher education institutions (HEIs) in 2017, publishing annual reports of results and findings. While the surveys gather both quantitative and qualitative data, the annual reports focus on the quantitative results and use select comments to provide some richness to the findings (Bates et al., 2017; Donovan et al., 2018; Johnson, 2019). The insights provided by the little qualitative data shared in these reports motivated us to inquire further into the collected data to explore whether qualitative data collected could offer additional insights into both digital education in Canada as well as into trends across the life of the survey. Therefore, we sought to conduct a systematic analysis of the narrative comments from the 2017, 2018, and 2019 datasets, anticipating that this analysis could deepen our understanding of the Canadian digital education landscape.

There are 234 publicly-funded postsecondary institutions in Canada, located throughout the ten provinces and three territories, with total student enrolment of approximately 2.11 million in the 2017-2018 academic

year (Statistics Canada, 2020). Within Canada's devolved governance system, education is a provincial/territorial responsibility. In this environment, a national approach to digital education faces a 
number of foundational challenges when it comes to jurisdiction, without even starting to examine the issues that a national digital education strategy would consider addressing. For instance, the postsecondary system in the province of Québec includes two distinct college designations-Collège d'enseignement général et professionnel (CEGEP) and private subsidized colleges-that other provinces do not have.

Results from the three pan-Canadian surveys conducted between 2017 and 2019 related to definitions of digital education, tracking enrolment data, technologies used, and the importance of digital education to the future of responding institutions (Bates et al., 2017; Donovan et al., 2018; Johnson, 2019). Reports reveal that digital education is evolving, as are the definitions used for online and blended/hybrid learning, reflecting changing practices. Challenges in tracking online enrolment data that arise from the different provincial/territorial reporting standards were also highlighted, noting that internal tracking processes used by HEIs to monitor progress are generally at the program or department level, making provincial/territorial and pan-Canadian comparisons difficult. Nearly all HEIs reported using a learning management system (LMS) and using it as the primary tool to deliver digital education, with video-based systems coming in second. The reports also drew attention to paradoxical findings in relation to institutions' long-term plans and strategies for digital education. While every year approximately two thirds of Canadian HEIs reported that online learning was very or extremely important to their future plans, the overall number of institutions with a fully implemented strategic plan for digital learning was small (e.g., 12\% in 2019). Each year, HEIs reported that they anticipated continued growth in digital and online learning, including fully online courses and blended/hybrid course offerings. In 2017, almost three quarters of HEIs reported that they offered blended/hybrid courses. By 2019, this number had increased to $89 \%$. Nonetheless, the 2018 report cautioned that fewer than one in five institutions had a significant number of blended/hybrid courses. Growth was also evident in fully online course offerings, with $10 \%$ growth reported in the 2019 report, even though overall course registrations remained stable. Finally, the survey results revealed emerging topics of interest in association with faculty development and training to use technology in teaching, advances in the development of alternative credentials, and adoption of open educational resources and practices.

\section{Objectives and Research Questions}

The aim of this study was to conduct a systematic analysis of the responses to open-ended questions from the annual surveys in order to provide a richer and multi-year view of digital education in Canada. The research questions were the following:

- What themes are present in open-ended comments with regard to digital education in the 20172019 CDLRA survey responses?

- Are there discernible patterns in these themes that change over time? 


\section{Method}

\section{Participants}

The CDLRA national survey was conducted in 2017, 2018, and 2019. The 2020 survey was cancelled due to the COVID-19 pandemic. The survey was sent to all publicly-funded postsecondary institutions in Canada, including universities, colleges, polytechnics, CEGEPs, and, starting in 2018, all private subsidized colleges in Québec. The number of institutions invited to participate, response rates, and the proportion of the total Canadian student population base represented is shown in Table 1.

\section{Table 1}

Responses to the CDLRA National Survey 2017-2019

\begin{tabular}{|c|c|c|c|c|}
\hline \multirow{2}{*}{ Year } & \multirow[t]{2}{*}{$\begin{array}{l}N \text { of HEIs invited to } \\
\text { participate }\end{array}$} & \multicolumn{2}{|c|}{$\begin{array}{l}\text { Response } \\
\text { rate }\end{array}$} & \multirow[t]{2}{*}{$\begin{array}{l}\% \text { of the Canadian student population base represented } \\
\text { by responding institutions }\end{array}$} \\
\hline & & $n$ & $\%$ & \\
\hline 2017 & 203 & 140 & 69 & 78 \\
\hline 2018 & 234 & 187 & 80 & 92 \\
\hline 2019 & 234 & 164 & 70 & 90 \\
\hline
\end{tabular}

Note. HEI = higher education institution.

Each year, the CDLRA sent the survey via email to institutional leaders (e.g., provost/VP academic) at every institution on the survey roster. In many cases, the results for each institution reflect the responses of multiple individuals.

\section{Data Collection}

Data for this study include all of the open-ended comments to the CDLRA national surveys from 2017 to 2019. At the time of writing, upon request by third-party researchers, the CDLRA made available deidentified and anonymized data it collected for secondary use. Prior to our analysis, the raw datasets were reviewed by the CDLRA and de-identified. The surveys included a total of 36 open-ended questions ( 9 for 2017; 16 for 2018; and 11 for 2019). The open-ended questions were optional and, in many cases, respondents left one or more of these questions blank. The open-ended responses analyzed for this study totalled 110,106 words (26,366 words for 2017; 61,977 for 2018; and 21,763 for 2019). Minor edits were made to the data for readability and spelling, without changing the intent or meaning of the data. French comments were translated into English and edited for accuracy, clarity, and completeness for analysis. 


\section{Data Analysis}

Data was analyzed in both a deductive and inductive manner, guided by the research questions and sensitizing concepts. Analysis included constant comparison of codes, identification of emergent themes, memo-writing about category and theme development, and iterative analysis. The open-coding process began with two researchers independently reading the data to become familiar with it; first, through an unstructured reading of the narrative data before a second reading, where they wrote open codes. This process allowed for emerging phenomena to arise from the raw data and was guided by Glaser and Strauss' (1967) constant comparative approach. During this process, researchers had access to the narrative data, the survey questions, and the three national reports. The questions and reports, while not original data, drew researchers' attention to contextual issues, important findings, and background ideas which informed the data analysis. These materials served as sensitizing concepts, offering researchers a sense of direction while making sense of the data (Patton, 2015). Through a series of iterative discussions with the entire research team, broad categories with codes and sub-codes were identified and defined for each individual year of survey responses. Next, the researchers refined the categories and developed a codebook with definitions for each category, code, and sub-code. The final codebook consisted of 8 categories and 84 codes, which were eventually collapsed into the themes presented below. To systematically analyze the data for this publication, a further round of focused and selective coding (Bogdan \& Biklen, 2007; Charmaz, 2006) was conducted independently by the same two researchers who conducted the initial coding. As data analysis continued, reports and tables were generated to organize, synthesize, differentiate, and compare patterns in the data. Where appropriate, themes were compared code by code in order to reach consensus between coders.

\section{Qualitative Rigour}

Careful consideration was given to procedures which would enhance the rigour and trustworthiness of findings by addressing accepted standards in the design, data analysis, and reporting of results (Patton, 2015). First, the data are available via CDLRA, enabling others to use and confirm the analysis reported herein. Second, authors ensured an audit trail by systematically documenting processes and materials (Freeman et al., 2007; Patton, 2015). Third, sensitizing concepts were used during the data analysis to organize the data and make informed decisions about the significance and importance of findings (Blumer, 1969). Fourth, to reduce bias in data analysis, team members analyzed data independently before collaborating in order to reduce the possibility of imposing individual biases and influence on other team members' interpretations. Fifth, reliability was addressed through constant comparison of findings at multiple points during data analysis and through discussions between researchers regarding the plausibility of findings (Merriam, 1995). Finally, findings are presented using thick descriptions to allow readers to determine whether findings from this study are applicable to their own contexts (Patton 2015).

\section{Limitations}

This study faces some limitations. First, the individuals submitting responses on behalf of participating HEIs could change from one year to the next, limiting not only the generalizability of findings between institutions but potentially the year-to-year comparison within the same institution. Second, the necessary process of de-identification eliminated contextual details, contextual indicators, and opportunities for member checking that could have aided in gaining a richer understanding of respondent comments. Finally, 
changes in survey items between years, in an effort to address emerging concerns and ensure the relevancy of the survey, limited a more detailed exploration of changes over time.

\section{Findings}

We identified six themes and describe these below.

\section{Growth of Digital Education}

Findings related to the growth of digital education draw from 185 comments across all three years of the survey. Several respondents noted areas where they see the potential for growth in either online courses or programs, such as in the trades. Many respondents also alluded to increasing interest in digital education among all students, regardless of whether they were studying on campus or at a distance, such as in the case of Respondent 56 (2019), who noted that "about one of every three students at our institution participates in an online course." Respondents also indicated that fully online programs were offered at multiple levels including undergraduate, graduate, and continuing education, in credit and non-credit programs. For example, Respondent 89 commented that their "institution offers fully online courses and programs including for-credit certificate programs" (2019). Institutions deliver their online programs along a continuum of a/synchronicity as evidenced in comments such as this: "Our courses are primarily delivered online in an asynchronous format" (Respondent 91, 2018). We also noted how, for some respondents, online program offerings are a priority, with comments such as these two: "We have committed to strategic investment in online and hybrid course development over the coming three years" (Respondent 126, 2017), and "Our institution will focus heavily on the development of fully online programs for the next three years" (Respondent 59, 2019).

Many respondents shared comments reflecting their intentions to be adaptable, responsive, and relevant to the needs of society, students, and potential employers by offering diverse course and program offerings which employ digital technology with effective pedagogical practices. For example, one institution stated that "online and blended fits with a larger strategy around flexible and authentic learning that dovetails into [our] experiential learning initiative" (Respondent 53, 2019). Another respondent noted that "online learning is particularly important in providing sustainable regional programming” (Respondent 13, 2019).

Numerous comments related to providing access to courses and programs for current and future students. Some were focused on the flexibility and growth opportunities that digital education can offer: "We see blended/hybrid learning as a key strategy that will allow for more flexibility for students and growth of our programs" (Respondent 9, 2019). Other remarks were about how online courses can enable students enrolled in programs in specific geographic locations to have access to courses or programs that might not otherwise be available to them. "The issue of accessibility of training is very important, and online training is likely to make learning accessible to remote communities that could not otherwise access it" (Respondent 241, 2017).

Finally, responses to questions asking about changes to the ways institutions offer digital education included comments around growth in course enrolments or increases in the types of courses and programs 
offered in online or blended/hybrid formats. For example, a typical comment was: "The number of students enrolled exclusively in distance learning courses is growing rapidly, as are students who combine classroom and distance learning courses to reconcile education, work and personal life" (Respondent 13, 2017). Some respondents elaborated with details on local circumstance: "As we continue to develop new online courses, our registrations continue to increase. However, we anticipate a leveling off to maintain a balance of online and face-to-face options for our students" (Respondent 112, 2017). Respondents also indicated future directions, as in "our institution will focus heavily on the development of fully online programs for the next three years" (Respondent 59, 2019) and shared explanations of how digital education was allowing them to address particular mandates (Respondent 104, 2019). In some instances, while institutions described having interest and experiencing growth in digital learning, they also noted that few of their offerings were in this modality. For instance, Respondent 92 noted that their institution "has considerable interest and growth in hybrid learning [but] when expressed as a percentage of our overall offerings, the portion is still less than 1\%" (2019).

\section{Adoption of OER and OE Practice in Canada is Supported Through Various Means}

Adoption of open education resources (OER) and practices (OEP) at Canadian institutions is present and supported at both the individual and institutional level. The majority of comments focusing on open education centered on open textbooks and OER. Most comments in these two categories simply mentioned use of OER at an institution without elaborating on such use (e.g., "Due to their open nature, OER exist in our institution in different forms and on different platforms." [Respondent 31, 2018]). Some respondents' comments provided further insight into how their institutions were implementing OER. One individual, for example, noted: "Our learning design process clearly articulates OER materials be considered at the course planning stage" (Respondent 26, 2017), suggesting that the OER adoption process at that institution is supported by broader structures and not solely reliant on faculty interests, desires, or passions. The clear picture that emerged from these comments was that OER use was uneven: while some institutions, for instance, featured OER champions (Respondent 76, 2019), in other instances, "the vast majority of faculty choose to use publisher resources" (Respondent 57, 2019).

From 2017 and 2018, we identified more comments indicating that institutions were in the early stages of OER use or that they were currently not using or pursuing OER. We noted some comments indicating low interest in OER (Respondent 125, 2017). In contrast, we coded a number of comments describing implementations, especially those of larger scale in 2019. A typical example of comments related to implementations was shared by Respondent 8 (2019) who stated: "There is significant interest amongst faculty. Many are exploring OER, and some are actively using OER.”

Comments revealed that there are a variety of ways that institutions champion OER, including through instructional design support, library services, funding, policy making, training and workshops, and workrelease from duties to free up time for adoption and creation of OER. The most frequently mentioned supports revealed that HEIs provide assistance and encouragement through policy making, funding, and library support for instructors. Many colleges and universities have institutional policies in place that include OER in some way. Respondent 5 (2019) indicated how their institution is "committed to developing an OER Strategy and embedding it within the Teaching and Learning Framework." A few participants remarked on policy-adjacent supports, such as Respondent 85 (2019) who noted that their "institution does 
not currently have a formal policy around OER. However, they do have a strategy that is elaborated in a guide for faculty."

In addition to policy and funding, libraries and centres for teaching and learning appear to be important sources of aid, advocacy, and overall institutional OER support. Nonetheless, despite some institutions developing OER policy and offering faculty support, OER use often appears to arise out of individual efforts and from a bottom-up approach. For example: "We are currently working with a handful of instructors who are independently using OER or have expressed interest in working with students to identify appropriate resources" (Respondent 141, 2019). There are also small groups bringing OER to the institution, with a handful of respondents sharing comments similar to Respondent 93 (2017), who noted "OER and open textbooks are currently being implemented on a small scale/pilot level," and another institution that described the adoption of these resources as "OER via grassroots efforts" (Respondent 77, 2019).

\section{Multidimensional Innovation in the Development of Digital Education}

The open-ended comments shared by respondents with regard to innovation in digital education at their institutions suggest that advances are occurring in various ways.

\section{Guided, Collaborative Approaches for Development of High-Quality Digital Education}

Across all years of the survey, 37 comments described how team approaches to course development were promoted at institutions. Respondent comments suggest that in many universities and colleges, professionals have shared responsibility for course design, development, and delivery. Collaborative approaches such as these bring together the expertise of subject matter experts, instructional designers, website developers, faculty, librarians, and educational media specialists. We noted that while reflecting on these team approaches, many respondents highlighted the shared expertise of professionals involved in course development processes in the 2018 and 2019 responses to the survey. A typical example is the following:

Faculty can work with an instructional design team who can provide out-of-the-box thinking on pedagogically relevant technology, content, graded and ungraded activities, and collaboration in a mode of delivery that students may feel more comfortable operating in (Respondent 17, 2018).

The collaborative course design processes described also included varied technological and nontechnological supports, such as in the case of Respondent 68 (2017) who mentioned that each online course developed "involves a four-person team-an instructional designer, graphic designer, front-end web developer, and a faculty expert" and is supported by LMS tools, HTML5, and various "third party tools, including Adobe products, Videoscribe, animation software, and other open source software."

Respondents also described a continuum in the autonomy accorded to those developing digital education experiences in HEIs across the country. In some cases, the course development process was directed with rubrics and other guidelines, such as the practices described here: "Faculty are guided by a blended learning reference document, which was developed following a two-year pilot of blended learning by a faculty member" (Respondent 25, 2018). Similarly, Respondent 16 shared that guidance was provided by a Centre for Teaching and Learning and that practices guiding course design included "frameworks, rubrics, and 
standards ... [as well as] instructional design principles" (2018). At the other end of this continuum, a handful of comments from respondents indicated that instructors were being left to their own devices to design online, blended/hybrid courses with minimal or no support or oversight. For example, Respondent 32 noted that, at their institution, "instructors often make their own choices regarding what technologies are used in their courses with some exceptions where the department determines what technologies are used" (2019) and Respondent 74 noted that "most courses were designed by individual faculty members" (2017).

\section{Innovations Remain Focused on Good Practices}

Survey responses appear to reflect thoughtful consideration being given to good practices in implementing new pedagogy or technology. Good practices in digital education extend beyond simply employing the newest educational technology or offering a different modality, to include practices which foster "student success and engagement and the adoption of universal design principles [which] are at the forefront of all of our teaching and learning experiences, including our online and hybrid offerings" (Respondent 66, 2019). There were many comments in all three years of the survey to support this perspective. For example, one respondent indicated that at the crux of these efforts are thoughtful considerations. They stated: "We have begun the process of encouraging faculty to integrate newly available technologies into their courses in a way that keeps teaching and learning best practices in mind" (Respondent 15, 2017). Another respondent indicated that their "libraries have introduced a new technology lending program for students and faculty, including virtual reality headsets [and] creative software application/invention kits ... encourag[ing] experimentation and creativity in curricular enhancements in simulation, labs, learning spaces, and course assignments (Respondent 126, 2017). Respondents also shared comments reflecting an awareness of the intersections between pedagogy and technology in the course design and development processes. For instance, sensitivity toward course design was expressed in many comments, such as in the case below:

Preparing an online course forces faculty to think carefully about course design and its connection to assessment that often leads to better in-person design as well. Digital affordances of online teaching have inspired greater interdisciplinarity, a wider range of perspectives in a course, and more pedagogical innovation in regards to student contact (Respondent 2, 2018).

\section{Institutional Strategies to Embrace New Technologies}

In every year of the survey, respondents described institutional strategies such as strategic, academic, or digital plans which encouraged faculty and staff to adopt new technologies. Although many institutions identified aspects of digital education as a priority at their institution, we noted few comments which reflected substantial progress in implementing these strategies, even though this may have been one of their institution's priorities for multiple years. A typical comment illustrating this from 2017 was the following: "We have committed to strategic investment in online and hybrid course development over the coming three years" (Respondent 126, 2017). In all three years of the survey, we identified similar comments around investing in new technologies, such as this one from Respondent 66: "Our current strategic plan (20182023) is very much focused on increasing how and when we integrate technologies into the curriculum and classroom experiences" (2019). This may reflect the fact that HEIs are in different stages of adoption, but may also reflect some digital chasms between institutions. 


\section{Emergent Digital Education Modalities and Technologies}

A variety of course delivery approaches were mentioned by respondents. While the vast majority were variations on blended/hybrid course delivery approaches, multi-access or hyflex (hybrid flexible) options, which offer a variety of educational choices and delivery methods, emerged in a handful of responses, with respondents noting that increased multi-access modalities might "better meet the needs of our students, whether they are here on-campus or living on the other side of the world" (Respondent 192, 2018). Adaptive models were another emergent modality mentioned by respondents as platforms that allow institutions to "build online courses that are more adaptive in nature, where students can enjoy a self-paced experience based on the mastery of learning outcomes and objectives" (Respondent 68, 2017). In addition to these emergent delivery models, respondents relayed details about the technologies their institutions have recently explored, are currently exploring, or are interested in exploring in the near future. Three technologies were mentioned: virtual, augmented, or extended reality (VR/AR/XR), mobile applications, and artificial intelligence (AI).

The most frequently mentioned emerging educational technology (6o coded responses) was virtual, augmented, or extended reality (VR/AR/XR). Respondents identified these platforms as useful in their near-future plans with comments such as: "We're looking more into XR [extended reality] applications for simulated labs" (Respondent 41, 2019) and "Our institution is developing Augmented and Virtual Reality initiatives" (Respondent 75, 2019). Nonetheless, institutions appear to be in the initial stages of incorporating these forms of technology into their digital education offerings, as evidenced by a number of comments that described exploring this technology. A second emergent technology noted by 23 respondents was mobile learning. Respondents noted that "students use mobile technology, even if courses or the LMS is not designed for such use" (Respondent 6, 2019). In response, some HEIs indicated that they have started looking for ways to respond or capitalize on this through their LMS, as evidenced in this comment from Respondent 14: "The Brightspace platform allows for the reformatting of material to accommodate the use of iPads and iPhones" (2019). Finally, AI was a prominent technology, mentioned by thirteen respondents. In doing so, respondents often noted some of the different purposes or functions they hoped AI could serve. For example, one respondent stated, "Our institution is developing a framework for assessing prior learning, identifying gaps, and using AI training modules to address the gaps” (Respondent 2, 2019). Other respondents commented on the potential for AI to provide technical support "to help support students (and perhaps faculty) in the use of online technologies" (Respondent 6, 2019) or academic support for student learning by "exploring the use of AI Tutor" (Respondent 82, 2019).

\section{Innovative Teaching in Digital Education in Canada is Situated}

While our analysis revealed numerous innovative digital practices, it also showed that such practices are situated within institutional contexts, and that there are substantial variations in the ways that respondents describe innovation. Significantly, what may be considered innovative in one context may not necessarily be innovative in another (cf. Veletsianos, 2016). We coded 180 responses over all three years focusing on innovative teaching practices in digital education.

Typical innovative teaching practices described by respondents across all years of the survey focused on the intersections of technology and pedagogy, pedagogical methods, course delivery formats, and student learning needs. Specific practices were, at times, mentioned, such as: "Using online simulations to provide 
students with opportunities to apply learning; Using online interactive case studies; Conducting presentations and seminars through synchronous and asynchronous tools" (Respondent 96, 2017); and "integrating active learning, creating gaming opportunities, using badging, producing video segments, building opportunities for reflections, etc." (Respondent 64, 2018). Further, one individual noted that the institution employed:

crowd-sourced marking generally, introducing more video conferencing with synchronous meetings for both instructors and students, working to allow more seamless integration of video and audio resources (especially for students) into course work (Respondent 97, 2019).

Respondents generally affirmed the important role of pedagogy in the innovative digital education approaches being developed. Technology was often described as a tool to support and facilitate these new practices, as in "Technology supports innovation when pedagogical considerations drive the use of the technology" (Respondent 6, 2018). Such thinking is also reflected in a number of respondents emphatically stating that "modality does not guarantee superiority" (Respondent 91, 2018). Statements like this revealed that respondents believed that no one course delivery modality was inherently better or worse, and that innovation could not be inferred strictly through the use of educational technology.

\section{Recognition of Quality and Rigour Concerns in the Broad Range of Digital Education Options Offered by HEls}

There were 78 open-ended comments that mentioned quality across the three years of the survey. In responses, we noted that HEIs were looking to make effective use of evidence-based resources to guide the course development process and address quality standards.

Respondents commented on technology and pedagogical decisions and a desire to make the best choices in terms of quality and rigour. This could mean sharing which digital education choices they feel to be the best, concerns with their current choices, re-evaluations, and future digital education plans and considerations. One of the most frequent types of comments that we coded for this theme was one that made mention of technology choices and the rationale for these decisions. This was articulated by Respondent 110 who wrote: "Our institution has been increasingly moving towards offering more courses using its LMS (Brightspace) to increase accessibility for remote communities, reduce the burden on physical space, provide more flexibility in delivery options, and make training available internationally" (2018). A second category of comments was associated with techno-pedagogical choices to improve rigour, such as the use of learning analytics to improve outcomes (e.g., Respondent 110, 2018). Finally, the third category of responses focused on how various pedagogical approaches that HEIs have identified contributed to the rigour of their digital courses. Respondent 97, for example, wrote:

It's true that some employers may value on-campus education more than online education, and it may be true that online education does not reach the standards of on-campus education at some institutions, but that is not our reality; we understand that the courses we deliver online are just as rigourous as the ones we deliver on-campus .... Our student persistence (or retention) rates are remarkably high, [and] both our new and experienced instructors have access to our [Centre for Teaching \& Learning] where they can get help (Respondent 97, 2018). 


\section{HEls are Developing a Broad Range of Alternative Credentials to Serve a Variety of Purposes}

Seventy-six comments in the dataset mentioned some form of alternative or micro credential, revealing that Canadian HEIs are exploring a broad variety of credentials which serve various functions. Badges were mentioned 23 times and were the most frequently mentioned alternative credential. While badges were described as being used in both individual courses (e.g., as incentives, Respondent 32, 2019) and as part of a program of study (Respondent 12, 2018), respondents indicated that alternative credentials served many purposes. These included using them as a dual credit with high schools; laddering options to other courses/programs; stackable credentials as a way to reflect updated skills and competencies; and as signifiers of co-curricular options for community-based or service learning experiences. Finally, some respondents noted that alternative credentials are means to other goals. For example, one respondent explained that their institution "is interested in exploring micro-credentialing as a strategy for curricular renewal and enhancing access to higher education" (Respondent 79, 2019). Thirteen respondents also described alternative credentials as a means to advance, pursue, or otherwise enable competency-based education efforts.

\section{Discussion and Implications}

These findings reveal common and typical practices and experiences in the Canadian higher education sector that shed additional light on the quantitative results reported by the Canadian Digital Learning Research Association over the years. As such, the implications of these results are broader than those offered by findings during a particular year of study.

\section{Complexity}

The increasingly complex nature of higher education is evident in respondent comments from all three years of the survey. Elements of complexity are not confined to technological advances (e.g., AI), but reach into other areas such as institutional and pedagogical processes. For instance, the use of OER and alternative credentials expands not only the number of activities that institutions engage in but also the nature of content and credentialing, and raises a variety of questions around data ownership, privacy, training needs, integration support, quality assurance, and evaluation methods. Further, such activities may include the disaggregation of higher education teaching, learning, and credentialing activities into various smaller components (e.g., course design and development or student support), further complicating higher education. Disaggregation appears to be common in digital education efforts (Czerniewicz, 2018) and is visible in some of the activities described above.

Such developments may speak to a broader willingness amongst HEIs to question established practices. Despite the likelihood of digital education initiatives raising various concerns, many HEIs appear willing to question institutional and pedagogical practices such as the use of traditionally published textbooks or the focus on typical credentials.

As digital education options grow at the institutional level, HEIs need to consider not just course design and support, but also student support. This may mean evaluating training needs, providing support for 
adoption, employing learning design and digital learning experts, and verbalizing the role that digital learning plays for the institution. Due to varying contexts, it is difficult to make recommendations for specific actions, but some of these may include the development of institutional policies around data ownership and privacy issues, the establishment of course design teams, the acknowledgement that such efforts may require more resourcing and different kinds of workloads for staff, administrators, and faculty, and so on.

\section{Contextual Innovations and Affirmation of the Important Role of Pedagogy}

HEIs reported a number of innovative teaching practices. While there were some commonalities among these, there were also variations. In some cases, what a HEI reported as a highly innovative practice in its setting may no longer be the case in another. Such variations in digital teaching practices may reflect disparities between institutions (e.g., access to pedagogical expertise), faculty training supports across sectors or regions, or even differences in mandate or institutional priorities. Innovations, therefore, need to be seen in context: what may be innovative at one institution may not be innovative in another. One significant implication of this finding is that innovations need to account for local conditions, implying that adopting innovations that other HEIs found worthwhile may not guarantee success. One finding appears to defy this implication. Specifically, as respondents at Canadian colleges and universities appear to affirm the important role of pedagogy in making decisions around the use of technology in their courses, it becomes clear that paying attention to pedagogy is significant across contexts. Pedagogical principles can guide adoption, innovation, and design, and this area offers much room for scholarly investigation.

\section{Contrasts in OER and OEP Support}

Respondents made frequent comments relating to OER adoption and the inclusion of OER in institutional policy. In addition to saving students money, OER are often offered as a vehicle to aid faculty in reimagining their courses and potentially impacting the teaching practices of those courses (Hegarty, 2015; Weller et al., 2015). Nonetheless, while participants described supports for OER, there was little to no mention of open educational practices (OEP) and supports provided to foster them. Cronin and MacLaren (2018, p. 137) contend that "expansive conceptualisations of OEP acknowledge the complex, actual and situated practices of teaching and learning," indicating that support for OEP may be necessary given its complicating nature and newness. One approach that HEIs may consider is to assess how OEP are being implemented and supported at their institutions. Again, this is a ripe area for future research.

\section{Variations, Unevenness, and Collaboration}

Findings suggest that there are variations and unevenness in digital education practice across Canada. Variations can be a sign of specialization, such as, for example, when institutions offer blended learning options for working professionals in their region compared to those institutions that employ online learning to reach out-of-region students. Unevenness may reflect a variety of issues, such as inequities in the higher education system (e.g., resourcing, digital literacies, etc.). Regardless of the reasons for the existence of variations and unevenness in the system, what institutional experience with COVID-19 has made clear is that the whole system can benefit from greater collaboration, synergies, and sharing of expertise. Between March and August of 2020, numerous faculty and institutions in Canada engaged in large-scale professional development efforts to support colleagues, both at their institutions and at institutions elsewhere, to design and develop remote courses. Such knowledge-sharing was significant and may have addressed some of the 
gaps and unevenness between institutions in terms of digital learning know-how. We hope that such efforts persist beyond the pandemic, and that they contribute to a higher education ecosystem that is more willing to share and collaborate.

\section{Conclusion}

The uptake of digital education in Canadian HEIs-partly arising from the COVID-19 pandemic, partly a result of ongoing efforts aimed specifically at online learning-makes the findings of this study timely and important. Based on the findings of this study, we recommend that approaches to digital learning in Canadian institutions be informed by contexts, including local, provincial, and pan-Canadian. Nuanced research of this nature, focused on Canadian HEIs at a time of widespread engagement with digital learning due to COVID-19, can provide evidence that researchers, faculty, and administrators interested in digital learning efforts need. 


\section{References}

Agbra, L. (2018, February 10). Online university programs in Canada: New options for students. Maclean's. https://www.macleans.ca/education/digital-classroom/

Bates, T., Desbiens, B., Donovan, T., Martel, E., Mayer, D., Paul, R., Poulin, R., \& Seaman, J. (2017). Tracking online and distance education in Canadian universities and colleges: 2017. Canadian national survey of online and distance education in Canadian post secondary education. Canadian Digital Learning Research Association. https://onlinelearningsurveycanada.ca/publications-2017/

Bates, T. (2018). The 2017 national survey of online learning in Canadian post-secondary education: Methodology and results. International Journal of Educational Technology in Higher Education, 15, Article number: 29. https://doi.org/10.1186/s41239-018-0112-3

Blumer, H. (1969). Symbolic interactionism: Perspective and method. Prentice-Hall.

Bogdan, R. C., \& Biklen, S. K. (2007). Qualitative research for education: An introduction to theory and methods (5th ed.). Allyn \& Bacon.

Charmaz, K. (2006). Constructing grounded theory: A practical guide through qualitative analysis. Sage Publications.

Cronin, C., \& MacLaren, I. (2018). Conceptualising OEP: A review of theoretical and empirical literature in Open Educational Practices. Open Praxis, 1O(2), 127-143. https://doi.org/10.5944/openpraxis.10.2.825

Czerniewicz, L. (2018, October 29). Unbundling and rebundling higher education in an age of inequality. EDUCAUSE Review. https://er.educause.edu/articles/2018/10/unbundling-and-rebundlinghigher-education-in-an-age-of-inequality

Donovan, T., Bates, T., Seaman, J., Mayer, D., Martel, E., Paul, R., Desbiens, B., Forssman, V., \& Poulin, R. (2018). Tracking online and distance education in Canadian universities and colleges: 2018. Canadian national survey of online and distance education in Canadian post secondary education. Canadian Digital Learning Research Association. https://onlinelearningsurveycanada.ca/publications-2018/

Freeman, M., deMarrais, K., Preissle, J., Roulston, K., \& St. Pierre, E. A. (2007). Standards of evidence in qualitative research: An incitement to discourse. Educational Researcher, 36(1) 25-32. https://doi.org/10.3102/0013189X06298009

Glaser, B. G., \& Strauss. A. (1967). The discovery of grounded theory: Strategies for qualitative research. Aldine Publishing. 
Hegarty, B. (2015). Attributes of open pedagogy: A model for using open educational resources. Educational Technology, (July-August), 3-13. https://upload.wikimedia.org/wikipedia/commons/c/ca/Ed_Tech_Hegarty_2015_article_attrib utes_of_open_pedagogy.pdf

Johnson, N. (2019). Tracking online education in Canadian universities and colleges: National survey of online and digital learning (2019 National Report). Canadian Digital Learning Research Association. https://onlinelearningsurveycanada.ca/publications-2019/

McGreal, R., \& Anderson, T. (2007). E-learning in Canada. International Journal of Distance Education Technologies, 5(1), 1-6. https://auspace.athabascau.ca/bitstream/handle/2149/744/elearning in canada.pdf? sequence $=1 \&$ isAllowed $=\mathrm{y}$

Merriam, S. (1995). What can you tell from an $\mathrm{N}$ of 1 ?: Issues of validity and reliability in qualitative research. PAACE Journal of Lifelong Learning, 4, 51-60. https://eric.ed.gov/?id=EJ497233

Mohr, S. C., \& Shelton, K. (2017). Best practices framework for online faculty professional development: A Delphi study. Online Learning Journal, 21(4). http://dx.doi.org/10.24059/olj.v21i4.1273

Patton, M. Q. (2015). Qualitative research and evaluation methods (4th ed.). Sage.

Seaman, J. E., Allen, I. E., \& Seaman, J. (2018). Grade increase: Tracking distance education in the United States. Babson Survey Research Group. https://onlinelearningsurvey.com/reports/gradeincrease.pdf

Statistics Canada. (2020). Canadian postsecondary enrolments and graduates, 2017/2018. https://www150.statcan.gc.ca/n1/daily-quotidien/200219/dq200219b-eng.htm

VanLeeuwen, C. A., Veletsianos, G., Belikov, O., \& Johnson, N. (2020). Institutional perspectives on faculty development for digital education in Canada. Canadian Journal of Learning and Technology, 46(2) 1-20. https://doi.org/10.21432/cjlt27944

Veletsianos, G. (2016). Defining characteristics of emerging technologies and emerging rractices. In G. Veletsianos (Ed.), Emergence and innovation in digital learning: Foundations and applications (pp. 3-16). Athabasca University Press.

Weller, M., de los Arcos, B., Farrow, R., Pitt, B., \& McAndrew, P. (2015). The impact of OER on teaching and learning practice. Open Praxis, 7(4) 351-361. http://dx.doi.org/10.5944/openpraxis.7.4.227

\section{Athabasca University}

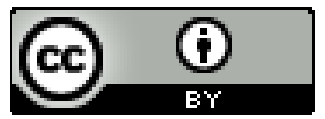

